\title{
Comparison of the Effects of Cardiac Rehabilitation Between Obese and Non-obese Patients After Acute Myocardial Infarction
}

\author{
Seung-Kyu Lim, $\mathrm{MD}^{1}$, Jae-Young Han, MD, PhD ${ }^{2,3}$, Yu-Ri Choe, $\mathrm{MD}^{2,3}$
}

\author{
${ }^{1}$ Department of Rehabilitation Medicine, Presbyterian Medical Center, Jeonju; ${ }^{2}$ Department of Physical and \\ Rehabilitation Medicine, Regional Cardiocerebrovascular Center, Chonnam National University Hospital, Gwangju; \\ ${ }^{3}$ Center for Aging and Geriatrics, Chonnam National University Medical School, Gwangju, Korea
}

\begin{abstract}
Objective To evaluate the effects of cardiac rehabilitation (CR) on functional capacity in obese and non-obese patients who have suffered acute myocardial infarction (AMI).

Methods Overall, 359 patients who have suffered AMI, and were referred for CR after percutaneous coronary intervention from 2010 to 2015 and underwent an exercise tolerance test before and after phase II CR were included in this study. The patients were divided into two groups: obese group with body mass index (BMI) $\geq 25$ $\mathrm{kg} / \mathrm{m}^{2}$ ( $\mathrm{n}=170$; age, $54.32 \pm 9.98$ years; BMI, $27.52 \pm 2.92 \mathrm{~kg} / \mathrm{m}^{2}$ ) and non-obese group with $\mathrm{BMI}<25 \mathrm{~kg} / \mathrm{m}^{2}$ ( $\mathrm{n}=189$; age, $59.12 \pm 11.50$ years; BMI $22.86 \pm 2.01 \mathrm{~kg} / \mathrm{m}^{2}$ ). The demographic characteristics and cardiopulmonary exercise capacity of all patients were analyzed before and after CR.

Results There were significant changes in resting heart rate $\left(\mathrm{HR}_{\mathrm{rest}}\right)$ before and after CR between the obese and non-obese groups (before $\mathrm{CR}, \mathrm{p}=0.028$; after $\mathrm{CR}, \mathrm{p}=0.046$ ), but other cardiopulmonary exercise capacity before and after CR was not different between the groups. $\operatorname{HR}_{\text {rest }}(\mathrm{p}<0.001)$, maximal metabolic equivalents (METs, $\mathrm{p}<0.001$ ), total exercise duration (TED, $\mathrm{p}<0.001)$, and maximal oxygen consumption $\left(\mathrm{VO}_{2 \max }, \mathrm{p}<0.001\right)$ improved significantly in the obese and non-obese groups after CR. No difference in the change in the cardiopulmonary exercise capacity rate was detected between the groups.

Conclusion CR may improve functional capacity in patients who suffered AMI regardless of their obesity.
\end{abstract}

Keywords Obesity, Myocardial infarction, Rehabilitation, Exercise test

Received March 14, 2016; Accepted May 3, 2016

Corresponding author: Jae-Young Han

Department of Physical and Rehabilitation Medicine, Chonnam National University Medical School \& Hospital, 42 Jebong-ro, Dong-gu, Gwangju 61469, Korea. Tel: +82-62-220-5198, Fax: +82-62-228-5975, E-mail: rmhanjy@daum.net

ORCID: Seung-Kyu Lim (http://orcid.org/0000-0002-6867-2896); Jae-Young Han (http://orcid.org/0000-0003-1672-8875); Yu-Ri Choe (http://orcid. org/0000-0001-5712-8724).

(c) This is an open-access article distributed under the terms of the Creative Commons Attribution Non-Commercial License (http://creativecommons.org/ licenses/by-nc/4.0) which permits unrestricted noncommercial use, distribution, and reproduction in any medium, provided the original work is properly cited. Copyright $\odot 2016$ by Korean Academy of Rehabilitation Medicine 


\section{INTRODUCTION}

Obesity is a highly prevalent chronic condition associated with significant morbidity and mortality [1-3], including increased risk for developing cardiovascular diseases, such as hypertension, heart failure, arrhythmia and coronary artery disease (CAD), as it has maladaptive effects on various cardiovascular risk factors and adverse effects on cardiovascular structure and function $[1,4,5]$. The prevalence of obesity between 1976-1980 and 20092010 among the world's population aged between 20-74 years has more than doubled due to changes in diet and daily life activities $[2,6]$.

Comprehensive cardiac rehabilitation (CR) is an effective secondary preventive post-myocardial infarction measure that can reduce the risk of re-infarction and cardiovascular mortality and morbidity [7]. The increase in the number of obese people has increased the overall risks for CAD. Overweight and obese patients account for $>80 \%$ of CR participants $[8,9]$. Obesity significantly alters the effectiveness of CR because of the increased risk for CAD and adverse effects on cardiac structure. Studies on Westerners have reported that both obese and non-obese patients revealed significant gains in functional capacity from CR $[5,10,11]$, and obese patients had smaller gains in functional capacity than non-obese patients $[10,11]$. Several studies have been performed on understanding the effects of CR on functional capacity in obese and non-obese Western patients; however, few studies have investigated the effectiveness of CR on functional capacity in Koreans.

The classification and the characteristics of obesity in Koreans differ from those of Westerners. The World Health Organization (WHO) recommends using body mass index (BMI) as a screening tool for obesity and defined overt obesity as BMI $>30 \mathrm{~kg} / \mathrm{m}^{2}$. BMI between $25-30$ $\mathrm{kg} / \mathrm{m}^{2}$ is considered as overweight based on data from Western populations [12]. However, a BMI of $25 \mathrm{~kg} / \mathrm{m}^{2}$ is considered as the cut-off for obesity in Koreans because these subjects have a higher percentage of body fat and thicker subcutaneous fat at a given BMI and are at substantial risk for comorbidities $[13,14]$. Results from the 2009-2010 National Health and Nutrition Examination Survey (NHANES) indicate that an estimated $33.0 \%$ of US adults aged $\geq 20$ years are overweight (BMI $25-29.9 \mathrm{~kg}$ / $\mathrm{m}^{2}$ ), $35.7 \%$ are obese (BMI $30-39.9 \mathrm{~kg} / \mathrm{m}^{2}$ ), and $6.3 \%$ are extremely obese (BMI $\geq 40 \mathrm{~kg} / \mathrm{m}^{2}$ ) [6]. However, the 2007 Korea National Health and Nutrition Examination Survey (K-NHANES) announced that the overall prevalence of obesity in Korean adults (BMI $\geq 25 \mathrm{~kg} / \mathrm{m}^{2}$ ) is $36.7 \%$ in men and $25.6 \%$ in women (i.e., $4.1 \%$ of men and women have BMI $\geq 30 \mathrm{~kg} / \mathrm{m}^{2}$ ) [15]. For this reason, we hypothesized that the effects of CR on functional capacity between obese and non-obese Koreans patients who have suffered an acute myocardial infarction (AMI) may differ from the effects in Westerners. Therefore, this study evaluated the effects of CR on functional capacity and BMI in obese and non-obese Korean patients who have suffered an AMI.

\section{MATERIALS AND METHODS}

\section{Subjects}

This study recruited 359 Korean patients who were diagnosed with AMI, treated with percutaneous coronary intervention at the Department of Cardiovascular Medicine of Chonnam National University Hospital, and referred to the Cardiac Rehabilitation Center of Chonnam National University Hospital, Gwangju, Korea from 2010 to 2015. We divided the patients into obese group (BMI $\geq 25 \mathrm{~kg} / \mathrm{m}^{2}$ ) and non-obese group (BMI $<25 \mathrm{~kg} / \mathrm{m}^{2}$ ) according to obesity criteria for Koreans. Before entering phase II CR, height and weight of each patient were measured, and BMI was calculated. All patients underwent exercise tolerance test (ETT) successfully before and after $\mathrm{CR}$, and completely finished phase II CR in 6 weeks.

\section{Program}

All patients participated in home- or hospital-based phase II CR program, which consisted of risk factor modification, home- or hospital-based aerobic exercise for 6 weeks, and an education and counseling program about psychological, vocational, and sexual aspects of recovery. Exercise sessions comprising of a 10-minute warm-up followed by 30 minutes of aerobic exercise, and a 10-minute cool-down were conducted for 50 minutes. The intensity of exercise was prescribed individually based on target heart rate (HR) calculated as:

Target HR=resting HR+(maximal HR-resting HR) $\times 0.4-0.85$

In addition, patients were encouraged to exercise at 
least three times per week. All patients who participated in hospital-based phase II CR program completed exercise sessions based on the prescribed exercise capacity under the supervision of a physical therapist. Patients who participated in home-based phase II CR program were also educated to perform appropriate exercises on a regular basis based on the prescribed exercise capacity and maintain an appropriate perceived exertion level based on their functional capacity evaluated before CR (light, moderate, somewhat hard) during exercise. They were guided to write down their exercise time and frequency in a pocket diary as a mean of confirming exercise performance. After CR, the diaries were collected.

\section{Measurements}

Clinical data of all enrolled subjects were collected retrospectively from their medical records, including patient's sociodemographic characteristics, type of myocardial infarction (e.g., STEMI vs. NSTEMI), medication (e.g., anti-platelet agent, $\beta$-blocker, angiotensin-convertingenzyme inhibitor [ACEi], and statin), ejection fraction (EF) from two-dimensional echocardiography performed during admission, and risk factors for AMI (e.g., diabetes mellitus, hypertension, hyperlipidemia, and smoking). All patients underwent the ETT on a treadmill (MedTrack ST55; Quinton Instrument, Fort Riley, KS, USA) using the modified Bruce protocol at baseline and after completing CR. We measured the patients' cardiopulmonary function at baseline and during the ETT using an integrated metabolic measurement system (TrueOne 2400 Metabolic system; Parvo Medics, Sandy, UT, USA), including resting $\mathrm{HR}\left(\mathrm{HR}_{\text {rest }}\right)$, maximal $\mathrm{HR}\left(\mathrm{HR}_{\max }\right)$, resting systolic blood pressure $\left(\mathrm{SBP}_{\text {rest }}\right)$, maximal systolic blood pressure $\left(\mathrm{SBP}_{\max }\right)$, maximal metabolic equivalents (METs), total exercise duration (TED), and maximal oxygen consumption $\left(\mathrm{VO}_{2 \max }\right)$.

\section{Statistical analysis}

The independent t-test was used to compare demographic characteristics between the obese and non-obese groups. The correlations between significant factors and obesity were evaluated by the chi-square test and Spearman correlation analysis. An analysis of co-variance (ANCOVA) adjusted for age was performed to compare

Table 1. Patients' demographics and characteristics

\begin{tabular}{|lccc}
\hline \multicolumn{1}{c}{ Characteristic } & Obese group $(\mathbf{n = 1 7 0})$ & Non-obese group $(\mathbf{n}=\mathbf{1 8 9})$ & p-value \\
\hline Age $(\mathrm{yr})$ & $54.32 \pm 9.98$ & $59.12 \pm 11.50$ & $<0.001^{* * *}$ \\
\hline Sex $($ male:female) & $147: 23$ & $149: 40$ & 0.058 \\
\hline BMI $\left(\mathrm{kg} / \mathrm{m}^{2}\right)$ & $27.52 \pm 2.92$ & $22.86 \pm 2.01$ & $<0.001^{* * *}$ \\
\hline MI type (STEMI:NSTEMI) & $68: 102$ & $77: 112$ & 0.887 \\
\hline Ejection fraction (\%) & $56.81 \pm 10.05$ & $56.72 \pm 12.78$ & 0.363 \\
\hline DM & $38(22.4)$ & $41(21.7)$ & 0.881 \\
\hline HTN & $70(41.2)$ & $76(40.2)$ & 0.853 \\
Hyperlipidemia & $27(33.5)$ & $59(31.2)$ & 0.641 \\
Smoking & $90(52.9)$ & $75(39.7)$ & $0.012^{*}$ \\
Alcohol drinking & $54(31.8)$ & $42(22.2)$ & $0.043^{*}$ \\
\hline Drug & & & \\
\hline Anti-platelet agent & $137(80.6)$ & $160(84.7)$ & 0.312 \\
\hline ACEi & $76(40.2)$ & $66(38.8)$ & 0.789 \\
$\beta$-blocker & $115(67.6)$ & $126(66.7)$ & 0.844 \\
\hline Statin & $101(59.4)$ & $102(54.0)$ & 0.145 \\
\hline
\end{tabular}

Values are presented as mean \pm standard deviation or number of patients (\%).

BMI, body mass index; MI, myocardial infarction; STEMI, ST-elevation myocardial infarction; NSTEMI, non-ST-elevation myocardial infarction; DM, diabetes mellitus; HTN, hypertension; ACEi, angiotensin-converting-enzyme inhibitor.

${ }^{*} \mathrm{p}<0.05,{ }^{* * *} \mathrm{p}<0.001$, for comparison between obese and non-obese groups by independent t-test. 
cardiopulmonary exercise capacity variables between the groups, and the paired t-test was used to compare before and after phase II CR in each group. The p-values $<0.05$ were considered significant. All statistical analyses were performed using IBM SPSS Statistics ver. 20.0 software (IBM Corp. Armonk, NY, USA).

\section{RESULTS}

Overall, 359 Korean patients with AMI were evaluated and were divided into obese (BMI $\geq 25 \mathrm{~kg} / \mathrm{m}^{2}, \mathrm{n}=170$ ) and non-obese group (BMI $<25 \mathrm{~kg} / \mathrm{m}^{2}, \mathrm{n}=189$ ). BMI and age were very significantly different between the groups (age: obese group $54.32 \pm 9.98$ years, non-obese group $59.12 \pm 11.50$ years, $\mathrm{p}<0.001$; BMI: obese group $27.53 \pm 2.92$ $\mathrm{kg} / \mathrm{m}^{2}$, non-obese group $22.86 \pm 2.01 \mathrm{~kg} / \mathrm{m}^{2}, \mathrm{p}<0.001$ ). Smoking pattern and alcohol drinking were significantly different between the two groups (smoking, $\mathrm{p}=0.012$; alcohol drinking, $\mathrm{p}=0.042$ ). No differences were detected for sex, type of MI, EF, drugs, diabetes mellitus, hypertension, or hyperlipidemia (Table 1). Number of old patients ( $\geq 65$ years; $n=90,25.1 \%$ ) was much less than young patients ( $<65$ years; $n=269,74.9 \%$ ), and young patients dominated in the obese group than the non-obese group $(\mathrm{p}=0.007)$ (Table 2). Smoking $(\mathrm{p}<0.001, \mathrm{r}=-0.297)$ and alcohol drinking $(\mathrm{p}=0.005, \mathrm{r}=-0.149)$ were negatively correlated with age (Table 3 ).

Significant improvements in $\mathrm{HR}_{\text {rest }}(\mathrm{p}<0.001)$, maximal

Table 2. Correlation between age and obesity

\begin{tabular}{cccc}
\hline & $\begin{array}{c}\text { Obese group } \\
(\mathbf{n}=170)\end{array}$ & $\begin{array}{c}\text { Non-obese group } \\
(\mathbf{n}=189)\end{array}$ & $\begin{array}{c}\text { Total } \\
(\mathbf{n}=\mathbf{3 5 9})\end{array}$ \\
\hline Age $(\mathrm{yr})$ & & & \\
$<65$ & $139(81.8)$ & $130(68.8)$ & $269(74.9)$ \\
$\geq 65$ & $31(18.2)$ & $59(31.2)$ & $90(25.1)$ \\
p-value & & $0.007^{* *}$ & \\
\hline
\end{tabular}

${ }^{* *} \mathrm{p}<0.01$, for comparison between obese and non-obese groups by chi-square test.

Table 3. Correlations between age, smoking and alcohol drinking

\begin{tabular}{lllc}
\hline & & Smoking & Alcohol drinking \\
\hline Age & $\mathrm{r}$ & -0.297 & -0.149 \\
& $\mathrm{p}$-value & $<0.001^{* * *}$ & $0.005^{* *}$ \\
\hline
\end{tabular}

$\mathrm{r}$, correlation coefficient.

${ }^{* *} \mathrm{p}<0.01,{ }^{* * *} \mathrm{p}<0.001$, by Spearman correlation analysis.
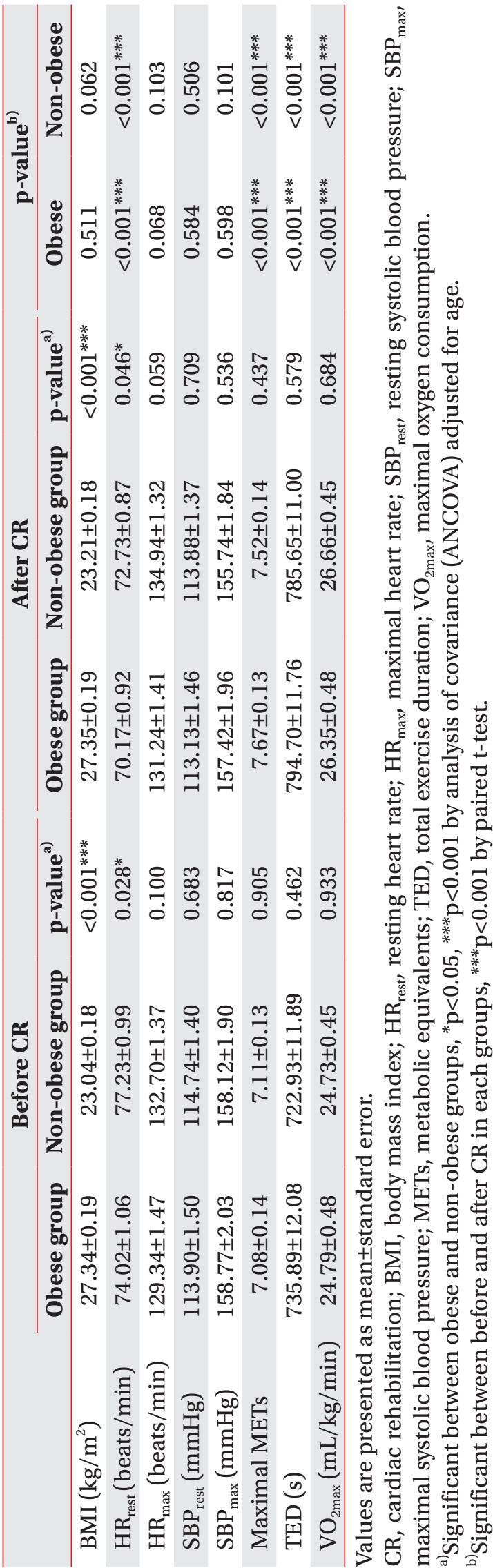

www.e-arm.org 
Table 5. Age-adjusted changes (\%) in rate of cardiopulmonary exercise capacity

\begin{tabular}{|c|c|c|c|}
\hline & $\begin{array}{l}\text { Obese } \\
\text { group }\end{array}$ & $\begin{array}{l}\text { Non-obese } \\
\text { group }\end{array}$ & p-value \\
\hline$\Delta \mathrm{BMI}\left(\mathrm{kg} / \mathrm{m}^{2}\right)$ & $0.08 \pm 0.31$ & $0.84 \pm 0.29$ & 0.078 \\
\hline$\Delta H R_{\text {rest }}$ (beats $/ \mathrm{min}$ ) & $-4.02 \pm 1.19$ & $-4.18 \pm 1.12$ & 0.925 \\
\hline$\Delta \mathrm{HR}_{\max }($ beats $/ \mathrm{min})$ & $2.06 \pm 1.0$ & $2.66 \pm 0.94$ & 0.665 \\
\hline$\Delta \mathrm{SBP}_{\text {rest }}(\mathrm{mmHg})$ & $0.73 \pm 1.32$ & $0.54 \pm 1.24$ & 0.916 \\
\hline$\Delta \mathrm{SBP}_{\max }(\mathrm{mmHg})$ & $8.09 \pm 1.88$ & $11.51 \pm 1.77$ & 0.192 \\
\hline$\triangle$ Maximal METs & $8.28 \pm 1.96$ & $12.41 \pm 1.85$ & 0.130 \\
\hline$\triangle \mathrm{TED}(\mathrm{s})$ & $11.82 \pm 2.48$ & $13.84 \pm 2.33$ & 0.559 \\
\hline$\Delta \mathrm{VO}_{2 \max }(\mathrm{L} / \mathrm{min})$ & $8.35 \pm 1.92$ & $11.26 \pm 1.80$ & 0.275 \\
\hline
\end{tabular}

Values are presented as mean \pm standard error.

$\Delta$, change in the rate of each variable before and after cardiac rehabilitation; $\mathrm{BMI}$, body mass index; $\mathrm{HR}_{\text {rest }}$, resting heart rate; $\mathrm{HR}_{\max }$, maximal heart rate; $\mathrm{SBP}_{\text {rest }}$, resting systolic blood pressure; $\mathrm{SBP}_{\max }$, maximal systolic blood pressure; METs, metabolic equivalents; TED, total exercise duration; $\mathrm{VO}_{2 \max }$, maximal oxygen consumption.

METs $(\mathrm{p}<0.001)$, TED $(\mathrm{p}<0.001)$, and $\mathrm{VO}_{2 \max }(\mathrm{p}<0.001)$ were observed in the obese and non-obese groups after CR. Cardiopulmonary exercise capacity from the ETT results at baseline and completion of phase II CR was not different between the groups, except for $\mathrm{HR}_{\text {rest }}$ (before $\mathrm{CR}$, $\mathrm{p}=0.028$; after $\mathrm{CR}, \mathrm{p}=0.046$ ), after adjusting for age as a confounding factor. No significant difference in maximal METs at baseline was detected between the two groups (obese group 7.08 \pm 0.14 ; non-obese group 7.11 \pm 0.13 ; $\mathrm{p}=0.905$ ) (Table 4).

In addition, the change in the rate of each cardiopulmonary exercise capacity variable was used to reduce error caused by differences in the baseline values, but no differences were observed between the groups after adjusting for age as a confounding factor (Table 5).

\section{DISCUSSION}

Obesity is a highly prevalent chronic condition associated with significant morbidity and mortality [1-3]. Obesity is an important and independent risk factor that increases the risk of developing cardiovascular diseases, including hypertension, heart failure, arrhythmia, and CAD because it has maladaptive effects on various cardiovascular risk factors and adverse effects on cardiovascular structure and function that increase arterial blood pressure, left ventricular hypertrophy, decreases insulin sensitivity, and adversely affects plasma lipid levels $[1,4,5]$. Despite the importance of obesity in the development of $\mathrm{CAD}$, very little information is available about the effects of CR on functional capacity between obese and non-obese Korean patients who have suffered an AMI. In this study, we demonstrated the effects of CR on functional capacity between obese and non-obese patients who have suffered an AMI.

In the present study, $47.3 \%(\mathrm{n}=170)$ of the Korean patients in CR were obese. This result was similar to that of study performed on Western patients (40\%) [5]. Our obese group was about 4.8 years younger than the nonobese group, but no differences in the prevalence of comorbidities such as hypertension, hyperlipidemia, or diabetes mellitus, were found in our cohort. The higher frequency of smoking and alcohol drinking in the obese group than the non-obese group observed in this study may be due to the difference in age between the groups. Obese patients are more vulnerable to chronic health conditions than non-obese patients [1,2], and the prevalence of obesity increases steadily among older age groups [16]. The differences between our study and previous reports are due to the "obesity paradox" between BMI and age. Some potential explanations for the obesity paradox were observed in our study. First, obese patients present earlier in the progression of AMI symptoms and undergo revascularization procedures at a younger age when compared to non-obese patients who have provision for more aggressive treatment during hospitalization. This may be due to concerns that they may be at increased risk for AMI or because of more severe symptoms due to increased myocardial demands that accompany excess weight [17]. Second, the paradox may be due to selection bias if only a subgroup of the "healthiest" obese patients is surviving to revascularization or being selected for revascularization [18].

The present study found no significant difference in functional capacity between the obese (METs, 7.08 \pm 0.14 ) and non-obese (METs, 7.11 \pm 0.13 ) groups at baseline before $\mathrm{CR}$, which is different from the concept that obese subjects have lower functional capacity and exercise performance than normal-weight subjects $[9,19]$. However, few studies showed rather lower functional capacity of non-obese patients in comparison to obese patients $[10,11]$. It is hypothesized that the difference may be 
due to the difference in age between the obese and nonobese groups, and participation of obese patients who would have a relatively lower risk for the ETT.

Our results show that obese patients may have attained significant and similar functional capacity (METs) and cardiovascular fitness $\left(\mathrm{VO}_{2 \max }\right)$ benefits as non-obese patients during phase II CR, as they could exercise longer after completing CR. In addition, no associations were observed between BMI and changes in the rate of any of the cardiopulmonary exercise capacity variables after adjusting for age, indicating that CR improved functional capacity (METs) and exercise performance in both the groups.

Our results are consistent with the findings of most of the reported studies $[5,11,20-22]$. Several studies reported that CR improves functional capacity in a consistent and significant manner $[9,21,23,24]$. Lavie and Milani $[5,11]$ demonstrated equal improvement in functional capacity in obese and non-obese groups after CR. They also reported that increase in $\mathrm{VO}_{2 \max }$ and improvement in peripheral muscle mechanics or work efficiency led to improvement in functional capacity [25]. Ades reported that general cardioprotective effects of exercise in patients with CAD might be due to enhancement in endotheliumdependent vasodilatation of coronary arteries [21]. CR can also improve adverse effects exhibited by obesity on many CAD risk factors, including arterial pressure, insulin resistance, plasma lipid levels, physical activity, and left ventricular hypertrophy [5].

However, considering the adverse effect of obesity on exercise performance, the finding in this study that obesity does not influence the effects of CR is difficult to interpret. As not all patients performed hospital-based aerobic exercise, there were some limitations in confirming exercise intensity, frequency, and total amount exactly. Patients might have performed less exercise than the prescription due to several reasons, or total quality and amount of exercise might have been different between the two groups. As explained earlier, obese patients were of young age than non-obese patients and might have been more willing to perform exercise, so there was a possibility that obese patients exercised more than prescribed.

Although there were no significant differences between both the groups, the non-obese group tended to show more improvements in $\mathrm{HR}_{\text {rest }}$, maximal METs, TED, and
$\mathrm{VO}_{2 \max }$ than the obese group. In general $\mathrm{VO}_{2 \max }$ increases about $10 \%-15 \%$ after CR [22]. Our obese group showed less improvement (8.35\%) in $\mathrm{VO}_{2 \max }$ as compared to previous studies. One study showed that obese patients have lower work capacity at both baseline and after CR [10]. Seres et al. [26] reported association between obesity and reduced exercise performance during each session, which could ultimately result in smaller gains in functional capacity during CR. Furthermore, they demonstrated that a large weight reduction in obese patients was associated with a marked increase in exercise capacity and increased TED and that obese patients performed the same amount of external work with lower cardiorespiratory response and energy consumption as compared to non-obese patients [26].

$\mathrm{HR}_{\text {rest }}$ is one of the most powerful predictors of cardiac mortality [27]. Obese patients have a significantly higher $\mathrm{HR}_{\text {rest }}$ than non-obese patients [28]. The higher $\mathrm{HR}_{\text {rest }}$ in obese patients is due to increased sympathetic tone and reduced vagal tone $[27,29]$. However, our results show that $\mathrm{HR}_{\text {rest }}$ was lower in the obese group as compared to non-obese group before and after CR. This result may also be due to the difference in age between the groups and our obese group had a younger population than the non-obese group. In addition, there is a probability that we made a mistake of including healthy people with lot of muscle mass in obese group based on BMI to classify obesity. Therefore, healthier obese patients having relatively lower risk for the ETT participated in CR. To a certain extent, significant improvement in $\mathrm{HR}_{\text {rest }}$ was observed equally in both the groups after CR, suggesting that a regular exercise program corrects the autonomic imbalance and improves cardiopulmonary exercise capacity regardless of obesity.

In contrast with previous study, we found no difference in the change in the rate of BMI after completion of CR in each group. Most of the studies have reported that CR reduces body weight $[9,11,20,23,24]$. This difference could be attributed to many factors including inadequate exercise performance, short duration of phase II CR, and inadequate diet. In addition, there is a probability that obese patients in this study were less obese as compared to the ones reported in western studies, because the definition of obesity in this study is not the reported BMI $\geq 30$ $\mathrm{kg} / \mathrm{m}^{2}$, but a BMI $\geq 25 \mathrm{~kg} / \mathrm{m}^{2}$. Furthermore, there can be a problem in simply applying a definition of BMI as $\geq 25$ 
$\mathrm{kg} / \mathrm{m}^{2}$ to Koreans, because the definition of obesity of Koreans is based on the WHO studies of obesity for Asian Indians, Chinese and Creoles in Asia-Pacific regions [30].

This study has some limitations. First, because this study was a single center study, the results in this study are difficult to accept as a general characteristic in Koreans. More structured multi-center studies are needed to represent characteristics of Koreans in CR. Second, in this study, phase II CR programs consisted of homeor hospital-based aerobic exercise. We recommended patients to perform hospital-based aerobic exercise to the extent possible, but most of the patients performed home-based aerobic exercise due to economical, occupational, geographical, or time factors. They were educated enough to exercise regularly and record their exercise time and frequency in a pocket diary provided by doctor, physical therapist and nurse. Most of the patients recorded their exercise performance and completed the prescribed amount of exercise, but some patients lost their diaries, or did not record, and not all the recorded data were reliable. There were some limitations in confirming exercise performance exactly, and the amount of exercise may not have been enough as prescribed. These discrepancies might affect overall functional capacity in both the groups after CR. Third, we used BMI, which is a measure of body fat based on height and weight, as it is the most commonly used tool in epidemiological studies. However, we did not account for peripheral or central adiposity, lean body mass, or body fat percentage because body weight is the sum of fat, muscle, visceral organs, and bone. Thus, misclassification of body composition using BMI would be expected to predispose our results. Further studies are needed to investigate the effects of CR on obesity using parameters, such as fat free mass index, waist circumference, and the waist-to-hip rate, to assess abdominal obesity. Fourth, this study was retrospective in nature and short-termed, so selection bias could have been present. No improvement was noted in either of the groups after 1 month of phase II CR. It is hypothesized that the follow-up period might have affected the changes in BMI after CR. More long-term follow-up is needed to understand the effects of CR on BMI and the association between changes in BMI and functional capacity in Koreans.

We hypothesized that the effects of CR on functional capacity between obese and non-obese Koreans patients who have suffered an AMI may differ from the effects in Westerners because of the racial and ethnic differences in diagnostic criteria for obesity and fat distribution as explained earlier. However, there were no significant differences in the results between this study and studies concentrating on Western areas due to differences in race and ethnicity. There are some limitations to conclude that the results in this study represent characteristics of Koreans. Nevertheless, results from this study show that CR can effectively improve functional capacity in obese and non-obese patients. Well-structured multi-center studies are needed to investigate the effects of CR on functional capacity in obese and non-obese Korean patients with AMI.

\section{CONFLICT OF INTEREST}

No potential conflict of interest relevant to this article was reported.

\section{ACKNOWLEDGMENTS}

This study was supported by the Convergence of Conventional Medicine and Traditional Korean Medicine R\&D program funded by the Ministry of Health \& Welfare through the Korea Health Industry Development Institute (KHIDI) (HI14C0862). This study was financially supported by the Electronic medical equipment part \& material industrialization foundation construction program through the Ministry of Trade, Industry \& Energy (MOTIE) and Korea Institute for Advancement of Technology (KIAT) (R0002662).

\section{REFERENCES}

1. Lavie CJ, Milani RV, Ventura HO. Obesity and cardiovascular disease: risk factor, paradox, and impact of weight loss. J Am Coll Cardiol 2009;53:1925-32.

2. Lavie CJ, McAuley PA, Church TS, Milani RV, Blair SN. Obesity and cardiovascular diseases: implications regarding fitness, fatness, and severity in the obesity paradox. J Am Coll Cardiol 2014;63:1345-54.

3. Jahangir E, De Schutter A, Lavie CJ. The relationship between obesity and coronary artery disease. Transl Res 2014;164:336-44.

4. Hubert HB, Feinleib M, McNamara PM, Castelli WP. 
Obesity as an independent risk factor for cardiovascular disease: a 26-year follow-up of participants in the Framingham Heart Study. Circulation 1983;67:968-77.

5. Lavie CJ, Milani RV. Effects of cardiac rehabilitation, exercise training, and weight reduction on exercise capacity, coronary risk factors, behavioral characteristics, and quality of life in obese coronary patients. Am J Cardiol 1997;79:397-401.

6. Fryar CD, Carroll MD, Ogden CL. Prevalence of overweight, obesity, and extreme obesity among adults: United States, trends 1960-1962 through 2009-2010. Hyattsville: National Center for Health Statistics; 2012.

7. Lawler PR, Filion KB, Eisenberg MJ. Efficacy of exercise-based cardiac rehabilitation post-myocardial infarction: a systematic review and meta-analysis of randomized controlled trials. Am Heart J 2011;162:57184.

8. Sierra-Johnson J, Wright SR, Lopez-Jimenez F, Allison TG. Relation of body mass index to fatal and nonfatal cardiovascular events after cardiac rehabilitation. Am J Cardiol 2005;96:211-4.

9. Bader DS, Maguire TE, Spahn CM, O'Malley CJ, Balady GJ. Clinical profile and outcomes of obese patients in cardiac rehabilitation stratified according to National Heart, Lung, and Blood Institute criteria. J Cardiopulm Rehabil 2001;21:210-7.

10. Gunstad J, Luyster F, Hughes J, Waechter D, Rosneck J, Josephson R. The effects of obesity on functional work capacity and quality of life in phase II cardiac rehabilitation. Prev Cardiol 2007;10:64-7.

11. Lavie CJ, Milani RV. Effects of cardiac rehabilitation and exercise training in obese patients with coronary artery disease. Chest 1996;109:52-6.

12. Obesity: preventing and managing the global epidemic. Report of a WHO consultation. World Health Organ Tech Rep Ser 2000;894:i-xii, 1-253.

13. Oh SW, Shin SA, Yun YH, Yoo T, Huh BY. Cut-off point of BMI and obesity-related comorbidities and mortality in middle-aged Koreans. Obes Res 2004;12:203140 .

14. Wang J, Thornton JC, Russell M, Burastero S, Heymsfield S, Pierson RN Jr. Asians have lower body mass index (BMI) but higher percent body fat than do whites: comparisons of anthropometric measurements. Am J Clin Nutr 1994;60:23-8.

15. Khang YH, Yun SC. Trends in general and abdominal obesity among Korean adults: findings from 1998, 2001, 2005, and 2007 Korea National Health and Nutrition Examination Surveys. J Korean Med Sci 2010; 25:1582-8.

16. Jura M, Kozak LP. Obesity and related consequences to ageing. Age (Dordr) 2016;38:23.

17. Bucholz EM, Rathore SS, Reid KJ, Jones PG, Chan PS, Rich MW, et al. Body mass index and mortality in acute myocardial infarction patients. Am J Med 2012;125:796-803.

18. King KM, Southern DA, Cornuz J, Maitland A, Knudtson ML, Ghali WA. Elevated body mass index and use of coronary revascularization after cardiac catheterization. Am J Med 2009;122:273-80.

19. Goran M, Fields DA, Hunter GR, Herd SL, Weinsier RL. Total body fat does not influence maximal aerobic capacity. Int J Obes Relat Metab Disord 2000;24:841-8.

20. Sadeghi M, Esteki Ghashghaei F, Rouhafza H. Comparing the effects of a cardiac rehabilitation program on functional capacity of obese and non-obese women with coronary artery disease. ARYA Atheroscler 2012;8:55-8.

21. Lavie CJ, Milani RV. Cardiac rehabilitation and exercise training in secondary coronary heart disease prevention. Prog Cardiovasc Dis 2011;53:397-403.

22. Lavie CJ, Milani RV. Effects of cardiac rehabilitation and exercise training on peak aerobic capacity and work efficiency in obese patients with coronary artery disease. Am J Cardiol 1999;83:1477-80.

23. Gondoni LA, Titon AM, Nibbio F, Caetani G, Augello G, Mian O, et al. Short-term effects of a hypocaloric diet and a physical activity programme on weight loss and exercise capacity in obese subjects with chronic ischaemic heart disease: a study in everyday practice. Acta Cardiol 2008;63:153-9.

24. Manzoni GM, Villa V, Compare A, Castelnuovo G, Nibbio F, Titon AM, et al. Short-term effects of a multi-disciplinary cardiac rehabilitation programme on psychological well-being, exercise capacity and weight in a sample of obese in-patients with coronary heart disease: a practice-level study. Psychol Health Med 2011;16:178-89.

25. Milani RV, Lavie CJ. Disparate effects of out-patient cardiac and pulmonary rehabilitation programs on work efficiency and peak aerobic capacity in patients with coronary disease or severe obstructive pulmo- 
nary disease. J Cardiopulm Rehabil 1998;18:17-22.

26. Seres L, Lopez-Ayerbe J, Coll R, Rodriguez O, Vila J, Formiguera $\mathrm{X}$, et al. Increased exercise capacity after surgically induced weight loss in morbid obesity. Obesity (Silver Spring) 2006;14:273-9.

27. Jouven X, Empana JP, Schwartz PJ, Desnos M, Courbon D, Ducimetiere P. Heart-rate profile during exercise as a predictor of sudden death. N Engl J Med 2005;352:1951-8.

28. Binder RK, Barth J, Schmid JP, Saner H. Burden of abdominal obesity in cardiac rehabilitation patients:
Results from the Swiss CaRe study. Swiss Med Wkly 2011;141:w13153.

29. Deniz F, Katircibasi MT, Pamukcu B, Binici S, Sanisoglu SY. Association of metabolic syndrome with impaired heart rate recovery and low exercise capacity in young male adults. Clin Endocrinol (Oxf) 2007;66:21823.

30. World Health Organization. The Asia-Pacific perspective: redefining obesity and its treatment. Sydney: Health Communications Australia; 2000. 